\title{
Karel Čulík
}

Сообщения. Жизнь и творчество Ладислава Ригера

Czechoslovak Mathematical Journal, Vol. 14 (1964), No. 4, 629-633

Persistent URL: http://dml.cz/dmlcz/100644

\section{Terms of use:}

(C) Institute of Mathematics AS CR, 1964

Institute of Mathematics of the Czech Academy of Sciences provides access to digitized documents strictly for personal use. Each copy of any part of this document must contain these Terms of use.

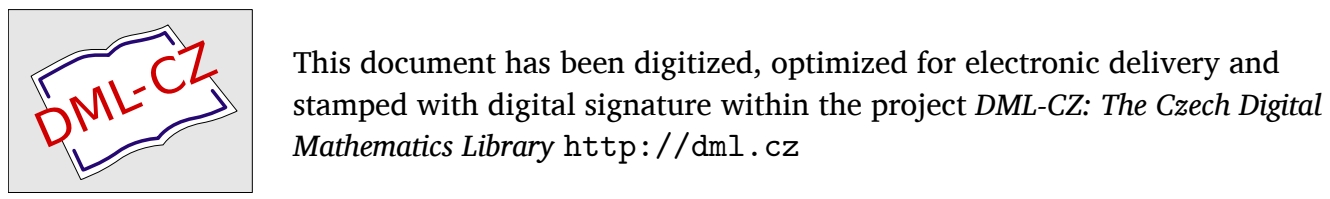


Чехословацкий математический журнал т. 14 (89) 1964, Прага

СООБЩЕНИЯ - NEWS AND NOTICES

\section{ЖИЗНЬ И ТВОРЧЕСТВО ЛАДИСЛАВА РИГЕРА}

КАРЕЛ ЧУЛИК, Прага

Ладислав (Сванте) Ригер родился 25 июня 1916 г. в г. Мальме в Швеции. Свою молодость он прожил в г. Розтоки и в Жилине. В 1935 г. Л. Ригер закончил среднюю школу. Его отец Ладислав Ригер, ставший позже профессором философии в Карловом университете, происходил из известной семьи Ригеровых.

Молодой Ладислав Ригер изучал математику и физику в факультете естествознания Карлова университета, где также принимал участие в левом студенческом движении (в „Обществе неимущих передовых студентов“). В 1939 г. чешские высшие учебные заведения были закрыты. его успешная учеба была прервана.

Во время оккупации Л. Ригер работал сначала статистическим вычислителем в Национальном банке; позже в 1943 г. он был послан в конструкторское отделение авиазавода „Авиа“. При этом он продолжал изучать математику и начал подготовлять свою диссертационную работу. Вместе с тем Л. Ригер работал в подпольной коммунистической печати и в нелегальной группе „Актив“.

После освобождения Л. Ригер стал ассистентом в Чешском высшем техническом учебном заведении, позже, в 1951 г. - доцентом математики. Степень доктора естественных наук Л. Ригер получил уже в 1946 г., а его диссертационная работа [1-3] в 1948 г. была удостоена премии Королевского чешского общества наук. В конце 1958 г. Ригер перешел из Чешского высшего технического заведения в Математический институт Чехословацкой Академии наук, где работал до своей преждевременной и неожиданной смерти 14 февраля 1963 г. В 1959 г. ему была присуждена ученная степень доктора физико-математических наук.

В своих первых работах [1-3] Ладислав Ригер рассматривал упорядоченные и циклически упорядоченные группы, но ряд последующих работ [5-8] был посвящен теории структур, главным образом булевым алгебрам. В этих работах была изложена структурная характеристика формулировки Гейтинга интуиционистской логики высказывания Брауэра, и изучались специальные свободные булевы алгебры и их конструкции. По времени и по тематике сюда принадлежит книга [27] ,О группах и структурах“. 
От булевых алгебр вел путь, естественно, к вопросам математической логи$\kappa и$, которой, впрочем, Ладислав Ригер уже долгое время интересовался. Решение посвятить себя этой области математики созрело, повидимому, во время его научной командировки в Варшаве в 1950 г. Во время этой командировки, имевшей большое значение для работы Ригера, его алгебраическое понимание некоторых вопросов предикативной логики вызвало большой интерес у ряда польских специалистов и некоторые из них исходили из этого понимания.

Алгебраизация математической логики является также весьма важной чертой ряда дальнейших работ, отчасти чисто абстрактно алгебраического, отчасти математико-логического характера $[9,12,13,15]$. В них вводится и изучается новое понятие обобщенной $\sigma$-алгеб $p ы$, а результаты сразу применяются к новому доказательству известной теоремы Гёделя о полноте. Аналогично вводятся еще более общие алгебры Суслина, и при этом снова в связи с вопросами математической логики, т. е. для описания квантификации предикатных переменных.

Приблизительно в 1954 г. Ригер начинает работать в области аксиоматической теории множеств, принципиальные вопросы которой уже давно привлекали его внимание. При этом он исходил из аксиоматики Бернайса-Гёделя.

Сюда принадлежит целый ряд весьма трудных, нередко также обширных работ $[16,18-22,24]$. Они касаются частично аксиоматической теории Гёделя, в частности значения некоторых аксиом, однако главным образом в них Л. Ригер занимается так наз. гёделевской аксиоматической теорией конечных множеств. Здесь построены особенных модели этой теории, имеющие несчетно много „конечных порядковых“ т. е. „натуральных“ чисел. Появляется новый аспект относительности аксиоматически определенного понятия конечности и понятия натурального числа, арифметики и т. д. Кроме того оказывается, что можно всю гёделевскую аксиоматическую теорию конечных множеств алгебраически вполне выразить при помощи обобщенных диадических чисел и их арифметики. В своей работе [24] Л. Ригер дал новое доказательство непротиворечивости аксиомы выбора и гипотезы континуума, где также освещаются некоторые методы Гёделя несколько с другой точки зрения.

Одновременно с работой над проблемами аксиоматической теории множеств Гёделя, которыми в последние годы больше всего интересовался, Л. Ригер также следил за новыми направлениями в математической логике, имеющими отношение к развитию быстродействующих вычислительных машин $[17,23]$.

Кроме того, в последние годы он интенсивно работал над монографией [30] об алгебраических методах математической логики. Еще задолго до подготовки этой монографии Ригер написал два ее предварительных варианта $[10,29]$ в качестве вспомогательных учєбных текстов. В наследстве было найдено шесть законченных глав и часть восьмой заключительной главы, первая вступительная глава полностью отсутствует, повидимому откладывалась на самый 
конец. В монографии подытожены существенные, полученные раньше, результаты по алгебраической логике; работа начинается основным вопросом математического языка и его символизации, описываются рекурсивные конструкции синтаксического отношения следствия между утверждениями символизированной математической теории и рассматриваются возможности такой символизации. Специальные алгебраические главы об алгебраической теории элементарной предикативной логики, об основах алгебраической теории логического синтаксиса и заключительная глава об алгебраических закономерностях семантики предикативной логики - эго вершина всей книги.

При последней обработке этих заключительных глав были введены и применены новые типы так наз. субствитутивно индексованных алгебр. Теория последних была подытожена в отдельной рукописи [25], также найденной в наследстве. Кроме того, в наследстве была найдена полностью написанная лекция [26] об основах математики и математической логики 20 века. Все эти работы будут в ближайшее время опубликованы.

В общем можно сказать, что Ладислав Ригер работал по двум основным направлениям. Первое направление составляют специальные булевы и другие абстрактные алгебры, второе - гёделевская аксиоматика бәсконечных и конечных множеств вместе со специальными арифметиками. О результате первого по времени направления можно уже сейчас сказать, что оно имело значительное влияние на развитие теории абстрактных алгебр, как это видно, например, из ряда цитат в монографии Сикорского о булевых алгебрах, в монографии о математической логике Гржегорчика и т. д.

Результаты второго направления, в котором Л. Ригер работал гораздо позже - последние результаты были опубликованы только после его смерти не нашли еще, понятно, полного применения. Согласно этим результатам и согласно существующему отклику можно ожидать, что они будут иметь существенное влияние на дальнейшее развитие аксиоматической теории множеств как у нас, так и за границей. Большой заслугой Ладислава Ригера является то, что именно в этом направлении много лет он руководил семинаром в физикоматематическом факультете Карлова университета и воспитал ряд работников, которые успшено продолжают его дело.

Ладислав Ригер занимался научной работой около 20 лет. Некоторые годы были неблагоприятными для этой работы. Л. Ригер однако умел глубоко и систематически сосредоточиться, а это было так необходимо для изучения весьма сложных и глубоких проблем, именно самые глубокие проблемы больше весго привлекали его внимание. Несмотря на то, что Л. Ригер все свое время посвящал научной работе, он очень внимательно следил за полиітическими и культурными событиями. Л. Ригер был всегда активным, убежденным сторонником коммунистических идей, при этом ему был всегда чужд догматизм в любой форме. Несмотря на то, что Л. Ригер прославил результатами своих работ себя и всю нашу математику, он всегда был необыкновенно скромным человеком. 
Он безразлично относился к почестям и званиям, мало обращаля внимания на то, что его деятельность, к сожалению, не получила вовремя признания, которое бы соответствовало ее чрезвычайному значению.

\section{СПИСОК РАБОТ Л. РИГЕРА}

А) Научные исследования

[1] O uspořádaných a cyklicky uspořádaných grupách, I (Об упорядоченных и чиклически упорядоченных групгах, I) Věst. Král. čes. spol. nauk, tř. mat.-přír., 1964, No 6, 1-31.

[2] O uspořádaných a cyklicky uspořádaných grupách, II (Об упорядоченных и чиклически упорядоченных группах, II) Věst. Král. čes. spol. nauk, tř. mat.-přír. 1947, № 1, 1-33.

[3] O uspořádaných a cyklicky uspořádaných grupách, III (Об упорядоченных и циклически упорядоченных грушпах, III) Věst. Král. čes. spol. nauk, tř. mat.-přír. 1948, No 1, 1-26.

[4] Použití matematické statistiky při vyšetřování nemocných včelstev (Применеине математической статистики при исследовании больных пчел). Zprávy čsl. zem. ak., 1947.

[5] A note on topological represantions of distributive lattices. Čas. pěst. mat. fyz. 74 (1949), $55-61$.

[6] On the lattice theory of Brouwerian propositional logic. Acta fac. r. nat. univ. Carol. 189 (1949), $1-40$.

[7] On free $\aleph_{\xi}$-complete Boolean algebras. Fund. Math. 38 (1951), 35-52.

[8] Some remarks on automorphisms in Boolean algebras. Fund. Math. 38 (1951), 209-216.

[9a] О счетных обобщенных $\sigma$-алгебрах и новом доказательстве теоремы Геделя о полноте. Чех. ма г. ж. 1 (76), 1951, 33-49.

[9b] On countable generalized $\sigma$-algebras with a new proof of Gödel's completeness theorem. Czech-Math. J. 1 (76), 1951, 29-40.

[10] O algebře nižšího predikátového počtu (Об алгебре нисшего предикативного исчисления). Размноженные лекции, изданные быв. Ústř. úst. matematický, Praha 1951.

[11] O marxistickém pojetí matematiky (О марксистическом толковании математики). Časopis pro pěstování matematiky 76 (1951), $75-103$.

[12] O jedné základní vědě matematické logiky (Об одной основной теореме математической логики). Čas. pro pěst. mat. 80 (1955), 217-231.

[13] Об алгебрах Суслина ( $S$-алгебрах) и их представлении. Чех. мат. ж. $5(80), 1955,99-142$.

[14] O některých základních otázkách matematické logiky (О некоторых основных вопросах математической логики). Čas. pro pěst. mat. 81 (1956), 342-351.

[15] Заметка о т. наз. свободных алгебрах с замыканиями. Чех. мат. ж. 7 (82), 1957, 16-20.

[16] A contribution to Gödel's axiomatic set theory, I. Czech. Math. J. 7 (82), (1957), 323-357.

[17] O teorii neuronových sítí (О теории нейроновых сетей). Apl. mat. 3 (1958), 243-274.

[18] A contribution to Gödel's axiomatic set theory, II. Czech. Math. J. 9 (84), 1959, 1-49.

[19] Problém tzv. absolutně nerozhodnutelných vět teorie čísel (Проблема т. наз. абсолютно неразрешимых теорем теории чисел). Čas. pro pěst. mat. 85 (1960), 1-13.

[20] Sur le problème des nombres naturels. Infinistic methods (Proc. Sympos. Foundations of Math., Warsaw, 1959), PWN, Warszawa, 1961, 225-233.

[21] Die axiomatische dyadische Arithmetik und ihre Modelle. Nachr. Österr. Math. Gesellsch. 15 (1961), Nr. 66, 84-85.

[22] A contribution to Gödel's axiomatic set theory, III. Czech. Math. J. 13 (88), 1963, 51-88.

[23] Ke Kleeneho normální formě strojově vyčislitelných funkcí (К нормальной форме Клина подходящих к вычислению на машинах функций). Čas. pěst. mat. 88 (1963), 349-363.

[24] On the consistency of the generalized continuum hypothesis. Rozprawy matematyczne 31 (1962), 1-43. 
[25] $\mathrm{Zu}$ den Strukturen der klassischen Prädikatenlogik. Zeitschr. f. math Logik und Grund!agen d. Math. Bd. 10 S. $121-138$ (1964)

[26] Základy matematiky a matematická logika 20. století - stručný náčrt hlavních směrů (Ocновы математики и математическая логика 20-ого столетия - краткий обзор главных нанаправлений). В печати: С̆as. pro pěst. mat.

В. Книги и учебные техсти

[27] O grupách a svazech (O группах и структурах). Sb. „Cesta $\mathrm{k}$ vědění“, T. 65, Přírodovědecké vydavatelství Praha, 1952, 208 страниц.

[28] Matematika II (для студен гов 2-ого курса фак. инж. машиностр.) SNTL. Praha 1955. (Учебный текст.)

[29] Matematická logika (Математическая логика). Размножение учебные тексты, изданные Мат. инст. ЧСАН. Praha 1961, 245 страниц.

[30] Algebraic methods of mathematical logic. (Готовится для издательства ЧСАН.)

\section{К ПЯТИДЕСЯТИЛЕТИЮ СО ДНЯ РОЖДЕНИЯ АКАДЕМИКА ШТЕФАНА ШВАРЦА}

18 мая 1964 г. исполнилось 50 лет академику ШТЕФАНУ ШВАРЦУ, профессору математики Словацкого высшего технического учебного заведения. В связи с этой знаменательной годовщиной за выдающиеся успехи в научной деятельности президент республики наградил академика Ш. Шварца Орденом труда. Свою 50-тую годовщину академик Ш. Шварц огмечает работой, которую уже выполнил для Словакии в области развития математики и которую далее в полном расцвете своих творческих сил продолжает выполнять. Академик Шварц является одним из известных основателей теории полугрупп. Благодаря своим работам в этой области он стал широко известным в научных кругах. Об этом свидетельствуют многие приглашения за границу, продолжительная поездка в США по приглашению некоторых американскых университетов. В последнее время академик. Ш. Шварц изучает с большим успехом топологические полугруппы. В 1955 г. за выдающуюся научную деятельность Ш. Шварц был удостоен Государственной премии Клемента Готтвальда. В Словакии академик Шварц воспитал много учеников, некоторые из них занимают виднье места в нашей научной жизни.

Поздравляем академика Штефана Шварца с его наградой и с его обширной научной и пецагогической деятельностью и желаем ему многих успехов в деле развития чехословацкой математики.

Редакция

\section{ЯРОСЛАВ КУРЦВЕЙЛЬ (JAROSLAV KURZWEIL), ДОКТОР НАУК - ЛАУРЕАТ ГОСУДАРСТВЕННОЙ ПРЕМИИ КЛЕМЕНТА ГОТТВАЛЬДА ЗА 1964 Г.}

30 апреля 1964 г. д-р ЯРОСЛАВ КУРЦВЕЙЛЬ, доктор наук, был удостоен Государственной премии Клемента Готтвальда, главным образом за разработку теории обобшенных дифференциальных уравнений.

Уже будучи учеником академика В. ЯРНИКА, Я. Курцвейль начал свою научную деятельность работами в области метрической теории диофантовых приближений. Несколько работ касалось приближений неразрывных функций, заданных в пространствах Банаха при помощи аналитических функций. С 1954 г. круг его интересов переносится на теорию дифференциаль- 